\title{
Crisis, Otherness and Integration. Local policies in South Eastern Europe: The case of Rhodes island
}

\author{
Panagiotis Kimourtzis \\ Associate Professor, University of the Aegean \\ Rhodes, Greece \\ Georgios Kokkinos \\ Professor, University of the Aegean \\ Rhodes, Greece \\ Ioannis V. Papageorgiou \\ PhD, University of Edinburgh \\ Rhodes, Greece \\ Dimitris Kypriotis \\ $\mathrm{PhD}$, University of the Aegean \\ Rhodes, Greece
}

\begin{abstract}
The density of the refugees and migrants wave in South Eastern Europe, along with the socioeconomic situation within and beyond Europe, shape the context and the agenda of the debate regarding the presence of Others in the European societies. The premises of that debate range from the practical considerations, such as the economic impact of securing the provision of essential necessities to the population in movement, to questions regarding the management of the integration of the current mixed migration flows. The conjuncture in which this debate occurs in the European level, namely the combination of economic crisis along with the emergence of centrifugal and xenophobe tendencies in many countries, render this debate significantly important. In an attempt to overcome the condensation of contradictions of the debate, innovative solutions could focus on researching and analysing the qualitative characteristics of the harmonic symbiosis between culturally diverse social groups at the local level. This article discusses the characteristics of the "embedded diversity" of the Muslim community on Rhodes island and its relations with the dominant Christian population and the new cultural diversity of refugees and immigrants. Based on that, the article analyses the significance of the local social conditions that could facilitate the integration of Others. The article concludes with indicative policy recommendations that base integration attempts on the particularly local social conditions.
\end{abstract}

Key Words: otherness, immigration, integration policies, Rhodes, Europe

\section{INTRODUCTION}

Eastern Aegean Sea islands are the first stop for a large part of the current population movement wave of the Muslim political and economic immigrants and refugees towards Europe. As for Rhodes, a Greek island in the Southeastern edge of Europe, the present condition constitutes a polymorphous challenge, since the island is a place of cohabitation of a dominant Christian majority and a local Muslim community which is present on the island since the $16^{\text {th }}$ century. Regardless of some issues, this symbiosis enabled the education of all 
children in the same schools, the dispersion of Muslim families across the island and their active participation in every sector of the economy of Rhodes. Our research has found tangible evidence of a "functional integration" of the cultural diversity of the "traditional Others", namely the Rhodian Muslims, in the local society. Therefore, in the present article it is important to discuss, whether the harmonious coexistence between the "traditional Others" and the dominant population group affects the integration of the immigrant newcomers. Ultimate purpose of the research is to examine the possibility of providing plausible policy suggestions for different places where already present culturally diverse social groups come in contact with the new diversity formed by migration. With that in mind, we discuss the appropriateness of policies that aim to empower local communities in reaching the "new Others".

Thus, this article will draw attention to the new landscape that shapes the coexistence with newly arriving Others in Europe before reflecting on the characteristics of the embedded diversity in Rhodes island, namely the community of Rhodian Muslims. Then it will discuss the importance of the particular social conditions formed in places where traditional and new diversities interact. Finally, it provides policy suggestions regarding otherness integration in the Greek society based upon the case study derived from the Rhodian multicultural environment.

\section{Old and New Features of the Coexistence Landscape}

\section{From euphoria to suspicion}

The interaction between members of the society and generally the societal processes, particularly in the presence of diversities (e.g. ethnic, religious, linguistic et al.), is a central challenge for the complex developed and modern societies. For that reason, the unhindered social interaction requires some degree of cohesion and solidarity, mutual understanding and trust among society members. It is what Robert Putnam (1993) has described in his version of the concept of "social capital". More social capital, greater trust and deeper understanding between insiders and Others allows for unimpeded social interaction. The contemporary intensity, characteristics and consequences of globalization, combined with the economic and refugee crisis, are key elements of the above considerations. This is because globalization, amongst others, accelerates social change, influences the distribution of wealth, raises powersharing issues, forms a more or less democratic framework for states to operate and, also, influences the shaping of cultural aspects in society (Held et al. 1999). Contemporary pressure, however, due to intensified migration flows, has raised concerns regarding the addressing of cultural heterogeneity. It has also caused a discussion regarding diversity on a cost - benefit basis. One can point for example to the 2010 statement by German Chancellor Angela Merkel that the "multi-culti society is dead" or the more recent statement from 2015 by the then Mayor of London Boris Jonson against the "multi-culti balkanization of the British society"i. And although not related to a new phenomenon, under the perspective of a new mass population movement, along with other new challenges emerging recently, integration issues and concerns raised in host countries seem to occupy more intensely a prominent position in the social debates, compared to the past (Ventura 2011).

Despite the fact that linguistic, ethnic and cultural diversity is characteristic of numerous countries around the world, the border crossing and settlement of the Others is a new painstaking process for almost all EU countries. In particular, today more than ever, coping with diversity has become a major political issue for the EU, as well as for each member-state, although for different reasons. And while, in terms of political rhetoric, Europe as statal and societal whole puts effort in avoiding the undermining of its identity as a region that attaches great importance to the eternal values of freedom, tolerance, multiculturalism and democracy. 
Today "xenophobias in Europe are multiple" (Balibar, 2011). Today in several EU countries fear, mistrust and polarization has spread possibly because of the scarcity of opportunities imposed by the financial crisis, prolonged stagnation and uncertainties in the labor market, together with massive migration inflows, as well as the rise of radical Islam and the dangerous generalization, resulting from attacks, that the West faces a general and constant terrorist threat (Balibar 2011). In order to understand the new context which affects diversity issues, we must take into account the coexistence of old and new features that shape today's complex landscape.

Traditionally, Others belong most frequently to the underprivileged, deprived and least educated part of the world, which a whole strand of academic writing refers to as the Global South (e.g. Dirlik 2007). Others also tend to attach particular importance to the issue of religion, because it constitutes the framework of their collective diversity (Taylor 2007). As a subgroup within the host country population they are often, self-evidently, treated with suspicion and skepticism. They also face integration problems in their destination countries and especially in the critical issues of education and children welfare. Finally, they attract academic interest which usually focuses on approaches raising the "identity" issue.

Throughout the $20^{\text {th }}$ century, experience from management of otherness in modern societies demonstrates that when the bottom line of cost-benefit discussion on diversity results to costs, they tend to be "charged" either on a social group and/or a specific region. On the other hand, those bearing the consequences of change are motivated to generate "skepticisms" or even "phobias". In that case raising "self-protecting" walls is only the next step in a gradual deterioration of openness to diversity. Taking into consideration that during recent years an agenda shift is evident in Europe towards economic and security protectionism (as of September $11^{\text {th }}$ 2001, but even more after the 2003 terrorist attacks in Europe), the asymmetrical refugee flows (Bellais 2016), coupled with the recession, have affected societies (Balibar 2011). Among those consequences are the increased xenophobia, non-tolerance, farright populism, toxic fragmentation of societies and reinforced nationalistic ideologies, which set off additional political charging to already complex issues. Hence, as they express disharmony and reflect multiple divisions in societies (i.e. moral, ethnic, racial, cultural, class), addressing otherness and integration are closely linked with high priority, but fragile, issues for the states.

Within this context, and while official EU rhetoric points to anti-discrimination, equal treatment of all social groups and encouragement of initiatives to strengthen multiculturalism and diversity, a distinctive situation is observed in regard to otherness. More specifically, there is a characteristic convergence towards skepticism, fear, anger and suspicion both in old and new member states, while in this new landscape the right to cultural difference becomes more distant. Tsibiridou (2011, p. 301) states that the dynamic challenge created by globalization determined the initiatives by both hegemonic and counter-hegemonic sources to use and treat difference. She argues that the multicultural policy approach in Europe has reproduced the ethnic and cultural diversity and along with it distinction and division based on those diversity indicators. The emergence of those indicators provided the opportunity to the Central European governments to redirect their reactionary policy towards segmentation or assimilation of the newcomers. In that context, the shockwaves by the economic crisis or by the continuing migration and refugee flows are variables that trigger a pre-existing "political fermentation", rather than the very cause of the issues. Of course, that doesn't apply to the southern periphery of Europe where the economic crisis and the refugee wave is very real. 
At the same time, religion has acquired a new role in many societies, where the dividing line with everyday life often becomes blurred. This in turn has highlighted issues that are colloquially ascribed to the "religionization of societies" (e.g. Peri 2012, Souryal 1987 and Bauman 2010) or even the reactivation of past religious hatreds. It has also raised concerns about re-addressing the relationship between state and religion (see for example the Muhammad cartoons controversy in 2005, the riots in Athens in May 2009, the Charlie Hebdo attack in 2015 and the Bataclan theater attack in Paris in 2015 or the Nice and the Berlin Christmas market attack in 2016). The massive movement of population towards Europe, multiplied the presence of different religious traditions in Europe. It is understood that as long as the nation-state seems to lose its central role in the determination of identity, religion takes over a new, empowered, role: it provides a sense of "belonging" beyond narrow geographic boundaries. This fluidity between concepts is demonstrated in the case of Northern Ireland where the national identity is contested in politically religious terms (Mitchell 2006 and Halikiopoulou 2007) and in the case of contemporary secularised European states that face difficulties in integrating the immigrant Muslim communities (Kurth 2007, Manzoor 2005 and Hai 2008). This facilitates the raising of walls between inner prototypical groups and outgroups, (Taras 2009) while extending unequal treatment and racial prejudice, often both ways.

Until recently, the EU-funded welfare state supported social or regional cohesion and solidarity policies to boost employment, enhanced health and education, addressed unemployment and poverty issues. Under certain conditions, those policies also covered the needs of particular population subgroups. Today, however, the steadily shrinking welfare state and the economic crisis, coupled with demographic pressures, exacerbates tensions that find new ways to be communicated. An inflation of "bottom up" channels exerts political pressure through peoples' participation. That development allows for greater involvement of individuals in decision making, thus shaping the "mainstreamisation" of either tolerant or othering opinions.

Within this context, European countries are evaluated for their ability to reduce divergence between various population groups and to safeguard a common language of co-existence. The bet, however, proved greater than the results, and, rhetoric is belied by reality.

\section{Otherness in a local sociohistorical context. The case of Rhodes}

\section{The presence of Rhodian Muslims}

As the macro-image of the social, political and economic conjuncture shapes the current dynamics of diversity between acceptance and otherness in a European level, what is missing is the dynamics at the micro-level. In the research project Understanding Diversity in Rhodes: Traditional and New Others (UnDRho), which has received funding from the EEA Mechanism 2009-2014 under Project Contract $n^{\circ}$ GR07/3635, we focused on the social formation of Rhodes island and the dynamics of diversity at the local level.

The Greek island of Rhodes is the centuries-long home of a local Muslim community. Despite the fact that the Islamic religion is present on the island since the $9^{\text {th }}$ century (Georgallidou, Kaili \& Celtek 2013, Kaurinkoski 2012, pp. 47-48, Tsitselikis 2011, p. 27 and Efthimiou 1992, p. 22), the siege and conquest of Rhodes by Suleiman the Magnificent in 1522 constitutes an important milestone for the Muslim presence on Rhodes. Across time there were several settlement efforts by the Ottoman administration, including that of Cretan Muslims in late 1890s (probably Islamised Christians). Nonetheless, the population balance on the island never changed with its main feature being the significant demographic dominance of Greek Orthodox Christians (Savorianakis 2000, p. 87, Tsitselikis 2011, p. 38, Andriotis 2004).

Throughout the Ottoman administration of Rhodes (1522-1912), although a demographic minority, the Muslims dominated politically. The public administration was based on a 
Kimourtzis, P., Kokkinos, G., Papageorgiou, I. V., \& Kypriotis, D. (2017). Crisis, Otherness and Integration. Local policies in South Eastern Europe: The case of Rhodes island. Advances in Social Sciences Research Journal, 4(5) 146-161

decentralised system with the ethno-religious communities (millets), which took over a variety of responsibilities including education and welfare, at its core (Appiah 2016). After 1912 and the Italian conquest, the religious communities retained their relative autonomy; though their purview was progressively curtailed. It is worth noting that during Italian occupation Dodecanese Muslims were able to choose nationality between the Turkish, Italian and that of Aegean islands (see Possedimenti Italiani dell'Egeo). Amongst approximately 11.000 Muslims, the vast majority (9.900) preferred the Rhodian identity, as opposed to 1.000 who chose the Turkish and 100 the Italian (Kaurinkoski 2012, p. 53), highlighting their attachment on the local identity against the national one. Later, the unification of the Dodecanese island complex, including Rhodes, with Greece in 1948 automatically ceded the Greek citizenship to all former "citizens of the Aegean islands".

Since 1951, Greek authorities do not collect demographic data regarding religion. This adds up to the already existing challenge of consistency of the available data regarding the size of the community. Nevertheless, as noted in bibliographical sources, Muslim population in Rhodes fluctuated between 4.000 and 6.000 members during the $19^{\text {th }}$ and the $20^{\text {th }}$ century (Krumbacher 1994, Savorianakis 2000, Dimitropoulos 2004, Tsitselikis 2006, Tsirpanlis 1998, Lantza 2011, Kaurinkoski 2012, Papadopoulos 2013). The last estimation from 1997 refers to 3.000 Rhodian Muslims (Chiotakis 1997). Significant variations in the population of the Muslim community appeared after the Dodecanese unification with Greece, mainly during periods of diplomatic crises (1955, 1964 and 1974) between Greece and Turkey (Kaurinkoski 2012, Lantza 2011).

The UnDRho project confirmed a recurring thesis in bibliography (Kaurinkoski 2012, Chiotakis 1997), that Rhodian Muslims are better integrated in the local society in relation to traditional (otherwise referred as historical) Muslim communities in Thrace, Greece. Historically, the Lausanne Treaty of 1923 conveyed the sovereignty on the area to Italy; as a result, the Muslim population of the Dodecanese was not included in the religion based population exchange between Greece and Turkey allowing the community to remain in its ancestral hearth. From a socioeconomic point of view, the dominant economic paradigm of mass tourism on the island directed the social dynamics towards extensively open and extra-communitarian relations influencing the intra-community code of communication. As Georgallidou, Kaili and Celtek (2006) claim, the reality has surpassed the ingroup and outgroup division; the "we" (Muslims) and the "Others" (Christians). As it will be seen in detail, this generally valid ascertainment is subject to qualitative differentiations.

Rhodian Muslims constitute a bilingual community, alongside some age and spatial differentiations. Older Muslims and residents of rural and suburban areas speak a local dialect of Turkish simultaneously with a variety of Greek. Younger generations use a newer version of this language; while, children prefer Greek accompanied by passive knowledge of Turkish (Georgallidou 2004, Georgallidou, Kaili \& Celtek 2011).

The evolution of bilingualism in connection with the development of Muslim education in Rhodes presents a strong case (although remaining merely a hypothesis). As already mentioned the organization of education was in the purview of the millets throughout the Ottoman period (Lantza 2011, p. 22) as well as after 1912 and the Italian administration, at least until 1937, when the curriculum came under central organization (Tsitselikis 2006, p. 74). During the brief phase of British administration (1945-1947) the communitarian educational system returned. In 1948 the integration of the Dodecanese with Greece introduced the Greek curriculum, although a parallel special one was introduced for the Muslim schools. The parallel curriculum operated generally without problems, though this was accompanied with strong debate especially during crisis in diplomatic relations between Greece and Turkey (Tsitselikis 2006 pp. 527-529). The fact that this balance was fragile was 
confirmed in 1972 when the Greek military coup reacted at the closure of the Greek schools in Turkey and discontinued the parallel curriculum.

Policies such as that in education, during the $20^{\text {th }}$ century imply the presence of "othering" processes for the Muslim community in Rhodes, regardless of the actual degree of integration. The relatively recent history of the autonomous religious community system demonstrates that this is neither new nor a unilateral process. The Rhodian Muslim diversity is an integral part of the local social formation; a social "functional diversity". Nonetheless, most subjects of the UnDRho research project reproduced well embedded social divisions in their everyday life. The Muslim community, therefore, constitutes a sui generis embedded "Other".

\section{Central characteristics of Rhodian otherness in the local society}

The empirical part of the UnDRho research project, conducted during Spring 2016, included, amongst else, eighteen in-depth qualitative interviews of Rhodian Muslims. These interviews combined a life narrative and semi-structure methodology. The interviewees were identified through snowball sampling but with a generational representativeness, while the research was triangulated through non-participant observation and content analysis of the interviews (Bryman 2004). Purpose of the empirical part of the project was to identify the qualitative characteristics of the Rhodian Muslim cultural diversity, examine under that light their stance against the new Others and test the interviewees' openness towards the integration of the novel diversity on the island.

What has been attested is that the experienced reality, between members of the dominant social group and the culturally diverse Others, is that of harmonious coexistence, although with subtle limitations, which is confirmed by Georgallidou, Kaili and Celtek (2006). In societies such as Rhodes, where coexistence between diverse communities dates centuries back, the common socialization and the participation in extrovert economic environment form a different portrait of diversity, and especially one that holds back prejudice. Kaili notes that in Rhodes "obviously, identity plays a role in certain circumstances but not in personal and everyday relationships" (in Mani 2008). For the rest of Greece, however, as the perception of the past organizes and structures the present (Chapman, McDonald \& Tonkin 1989, pp. 4-5, Sutton 1998, p. 4 and Anderson 1997, p. 15), the Ottoman past, with all its negative connotations, is related to the modern day "Turks". The case of Rhodes, demonstrates that the long confrontation with otherness constraints it in the space of the imaginary, despite being reflected in textbooks and blurry oral traditions.

The Muslim diversity in Rhodes is multi-dimensional, although perceived as a homogeneous group. On the one hand, there is a generational difference in the way Muslims make sense of their integration since younger generations tend to assimilate to the dominant identity (Georgallidou, Kaili \& Celtek 2006). A significant dissimilarity appears, however, between the Cretan Muslims in Rhodes and the largest part of the community. It regards the language parameter, as Cretans do not speak Turkish but Greek.

The intergenerational differences apply also to the extent to which the cultural diversity is combined with national self-determination. A general finding is that older Rhodian Muslims are not willing to break their emotional ties with the neighboring country (Turkey) to the degree that those ties constitute the very "tradition" of the community and the imprint of the Ottoman presence of the island (see also Kaurinkoski 2012, p. 52), the names of specific locations and monuments, the language etc. On the contrary, younger generations e.g. are not keen to learn Turkish, while they also largely refrain from involvement in Muslim faith. 
Cowan and Brown (2000, pp. 3-27) argue that distinct social groups cannot be described as established and compact classes because of their significant internal differentiation. As a matter of fact, Rhodian Muslim identity is a complex formation structured by wider identities antagonistically positioned. Their Rhodian identity prevails that of religion or national identity. Nonetheless, most Rhodian Muslims stand somewhere between their religion, their ethnic consciousness, their social environment and their Greek citizenship. The younger generation of Rhodian Muslims abandons Muslim community "tradition" and adopts the social norms of the dominant population. In other words, younger Rhodian Muslims, look towards secularization of the society, in which cultural and religious differences either disappear or become completely insignificant.

\section{The intergenerational aspects of otherness among Rhodian Muslims}

UnDRho empirical research identified three ways in which Rhodian Muslims make sense of their identity, associated with language and religion (as primary components of the cultural capital) and lifetime experiences accumulated by different generations.

For the middle-aged Rhodian Muslims, education and language are the concepts through which they approach their diversity. The development of the Muslim educational policy and more specifically the parallel curriculum, have contributed to maintaining a degree of social separation. With the abolition of the community autonomy, social differentiation was maintained only on key manifestations of the cultural capital: religion and language. The institutionalization of that diversity in the parallel curriculum marks the particular way in which middle-aged persons make sense and experience otherness.

Interviews with middle-aged members of the Muslim community clearly led to three conclusions. They experience the lack of official education on the Turkish language as a reduction of their cultural capital. Their contact with religion falls short compared to the language issue. Their desire, however, to be educated in Turkish is rationalised both through the need to learn their mother tongue and as the positive results from learning several foreign languages. Therefore, middle-aged Rhodian Muslims experience otherness on a linguistic basis and express their concern regarding the progressive distance of the younger generations from the community's cultural capital on the same basis. Interestingly, the parallel curriculum as educational policy did not receive any positive or negative comment, apart from one respondent who argued in detail against the learning results of that system.

The situation for the older members, however, is different. Our interviews demonstrated that references to religion among them presented a repetitive emphasis. While twofold reference patterns of the type "we/you" were common among middle-aged and older Muslims, the "Christians/Muslims" pattern was mentioned by the latter. At the same time, although religion gave meaning to their account of diversity, older people kept on narrating their family history placing emphasis on their aristocratic origin, fortune or social role of their ancestors. Religious references were the "vehicle" with which that social background was articulated. The ancestral graves, the family fortune donated to religious foundations (Waqf) or the family members that became congregation ministers (Hodja) are indicative and recurring references. Thus, one notices a "delicate association" between Muslim religious diversity and social status among elders. Religion is either the way in which the "glorious past" continues to date or the "trustee" of the family history. This may be the result of the historical and political circumstances marking the period in which the socialization of the respective generation took place and more specifically, during the period of the embedded social categorizations of the millets (Tsitselikis 2006, Walzer 1999). Given the relation between religious communities and political 
sovereignty, the memory of social hierarchies survived in religious terms and images. This is indirectly confirmed in the case of a middle-aged interviewee, who, after 1947 migrated in Turkey and Germany. Although younger than the group of the older interviewees, he retained the "glossary" of ideas with which social hierarchy is negotiated through religion.

Younger Rhodian Muslims experience the institutionalization of their diversity in a different way. The latter act and think from a distant cultural setting compared to other generations, as they do not speak Turkish and in religious terms -like the Rhodian majority- they are among those "belonging, but non-believing" (Karamouzis 2015). In fact, unlike the elderly, in their case religion cannot in any way manifest social stratification. As they disconnect from the Muslim cultural capital, they find themselves in the awkward position to rationalise, but not empathise, with the social stereotypes that derive from the manifested features of their cultural diversity. Interviewees for example have noted the awkward moments when they introduce themselves since their names are manifestations of their religion.

Young Rhodian Muslims' struggle to make sense of their cultural identity in Rhodes is not always a cause for concern. Instead, our research recorded cases in which, as a subconscious strategy, young Muslims gave meaning to their cultural diversity by attending the religious courses at schools, although exempt from this obligation. Their participation during the course offers the perspective of another religion in the class, while supporting them with a sense of being useful in this process. The actual presence of diversity in the classroom is a factor of plurality in the educational system on the one hand and individual empowerment on the other. Young Muslims experienced "small victorious moments" in which their diversity becomes something more than functional; it becomes valuable for the social environment of the classroom. This is a kind of individual and cultural empowerment that could become less coincidental and more instigated in the case of the new Others, namely immigrants and refugees.

\section{New diversity in the eyes of the traditional}

The new diversity of refugees and immigrants in Rhodes island constitutes a novel variable that allows for reconsidering the concept of otherness in both its traditional, as well as its new and developing form.

The empirical research of the UnDRho project indicates that the shared experience of diversity or the mutual religious references between Rhodian Muslims and Muslim refugees and immigrants cannot form the emotional basis of acceptance of the new outer group. Interviewees from the traditional Others on Rhodes island, being a prototypical inner group (Taras 2009), were adamant that common religion cannot cover dissimilar cultural references. In fact, although a humanitarian approach regarding the immediate needs of refugees and immigrants is nonnegotiable among the interviewees, prejudice against integration is indeed a widespread point of view. According to most of the views, fear from the extent of the phenomenon, the finiteness of the Rhodes island resources and the deep economic crisis of Greece come at odds with the size of the mixed migration flows. The interviewees repeated that Greece's problems constituted unlikely any extensive help, both financial and in-kind, for immigrants and refugees. Yet, only very few respondents reported security concerns related to the shifting populations. In any case, according to the interviewees, competence, as well as effective ability to address the phenomenon lies in state structures; the associations representing the Rhodian Muslim community are rather weak to offer any kind of supporting services. 
The following trends which correspond to three "cycles" of interviewees were identified. The first one reflects the views of the Rhodian Muslim cultural association. Its members tend to express the greater concern regarding migratory flows on the island and its potential to absorb the financial shock caused by an integration policy. The second cycle resonates the most religious among the Rhodian Muslims. They present the most humanitarian stance being greatly concerned about the urgent needs of the newcomers. Still, they cannot picture the Muslim community's role in the administration of the problem. The third trend is comprised by the group of those who don't participate anyhow in the public aspects of the community. Despite their empathy for refugees and immigrants, they are concerned about their potential religious extremism, along with the more conservative views of Muslim refugees and immigrants.

Those ascertainments resonate the work by Taras (2009) who, in the process of examining the psychological readiness to allow newcomers enter something prototypically connected to the older members of a group, he coins the distinction between ingroup prototypicality and outgroup derogation. At the same time, we find an analogy with Madibbo's research (2007) on the integration of Francophone Caribbean immigrants in the Francophone minority of Ontario, Canada. As in the case of Rhodes, a common cultural characteristic, namely the language in Ontario and religion in Rhodes, is not enough to initiate the readiness of the prototypical ingroup to allow the new Others in the community's institutions. The reason might be found in the process of religious de-institutionalization taking place during the last centuries in Europe, that structures a sui generis secularization (Gole 2013, Roy 2013, Barnavi 2008). Within such context, European Muslims, including the Rhodian community, were able to adapt through the dynamic interplay of the public, private and personal spheres taking place in Europe during modernity. Muslim immigrants on the other hand are asked to readjust their relationship with religion by "objectifying" Islam, namely by defining the ideological part against disappearing culturally embedded institutional structures (Roy 2013). In that way, when successfully integrated, Muslim immigrants in Europe participate in a double cultural capital (Gole 2013); but, when unsuccessful, they may become susceptible to extremism (Roy 2013). In fact, as religion becomes one of the "bridges" from which the public sphere colonises the private one, it becomes a legitimization vehicle either for the tolerance or the resistance of that colonization.

\section{National issues and local solutions: Examining policies that can work}

The multiple levels of making sense of otherness among older, middle-aged and younger Rhodian Muslims and the consequent configuration of subconscious strategies that have been developed to make sense of diversity, are instrumental in developing local policies for the integration of refugees and migrants. The bidirectional integration process that on the one hand enables cultural plurality in the social formation and on the other supports individual empowerment is an act of restoration of justice against the marginalised Other in general (Günther Anders in Cassin 2015, p. 102). The realisation of integration and empowerment, however, is a complex process that needs to take into consideration the particularities of the local social formation.

\section{Beyond policymaking: key elements to reflect upon}

Upon the cumbersome task of addressing the needs of social groups which share their diversity but not their cultural premises, namely the local or traditional Others and the new Others, policymaking needs to take into consideration the following sevenfold mix of principles:

Policies need to address both the pressure from the current refugee/migration crisis and at the same time reflect on the historical, philosophical and religious aspects of the coexistence of culturally diverse groups as well as the social and political conjuncture. 
In Greece, a worrying increase of the fear of the Others hinders coexistence with immigrants/refugees (Greek Ombudsman 2013). At the same time, however, positive "cultural reflections" are evidenced among a sizeable part of Greeks that demonstrates solidarity towards immigrants and refugees (Papataxiarchis 2016).

The "rule of law" and more specifically the "equality and fairness before the law" need to be a guiding principle of the formed policies. Practically, a non-discriminatory and non- exclusive provision of support would ensure respect for diversity based on existing national legislation within the European Union context.

Integration policies have an important local dimension since they are centrally planned but locally implemented. As long as the integration of Others, the molding of harmonious social coexistence and the strengthening of conditions of social cohesion is realised at the local level, the role of local government and civil society is markedly important: they can highlight challenges, address/prevent conflicts and generate creative opportunities for the coexistence of both Us and the Others.

The design of policies should be the result of a bidirectional approach. A bottom-up approach would give voice to the "voiceless", while a top-down one would counterbalance the overgeneralization by narrowing down the analysis through the overview of the caveats of the field research.

Policies should also equally take into consideration both refugees and immigrants. Despite the legal dissociation, those social groups face similar difficulties when settling in the host country. Moreover, they share the same determination to build an entirely new social environment -by settling to a new country- and similar ambitions to develop personal, professional or cultural elements that facilitate adjustment into their new environment, overcoming complex problems and even troublesome traumatic experiences.

In a similar vein, policies should overcome the distinction between legal and illegal migration that results to the distinction between integration and exclusion. While this distinction is real, a framework of inalienable human rights is nonnegotiable.

Policies should emphasise on a dynamic collaborative process that requires mutual effort between the host community and the Others (old and new). Moreover, this effort should demonstrate persistence and willingness to align with widespread democratic values and dominant cultural context.

\section{Through the lens of reality: the local dimension of contemporary migration}

The Rhodian Muslims case confirms that integration relates, amongst else, to the way that social conditions are experienced. Bearing in mind the size of the current migration flows, it is quite interesting that at local level our research identified a generally compassionate public opinion; supportive humanitarian activism by volunteers and organizations; solidarity practices and empathy. Those ascertainments can support realistic and successful solutions that relieve direct and indirect needs without triggering discontent among the majoritarian social group.

Moreover, local communities often operate as social laboratories committed to developing strategies of coexistence. However, while local communities shape their inhabitants' realities, it must be emphasised that the difficulties to capture the range of challenges and even more to address them are not necessarily reduced. Population flows are constantly changing and difficult to predict. This in turn makes it even more difficult to understand their needs, to build strong ties with them and to formulate effective integration policies. It is also critical to address the danger posed by the tendency for geographical concentration of the newcomers that can possibly turn into ghettoization. The local communities are called to establish communication links with those groups to prevent marginalization. The case of the development of relations 
between Christian and Muslim communities in Rhodes demonstrates both the feasibility and the need for such an approach.

It is understood that population flow concerns also the movement of ideas, culture, experience and generally of the movement of capital; social, cultural, and economic. That is precisely why the success of the community social laboratory depends, respectively, on several elements. Key to success is how all the necessary factors fit together within the local context. For example, how the public, private and non-profit sectors interconnect under adequate governance resulting in evident added value and benefit the entire society while avoiding overlapping and mutually canceled efforts. What is required locally is a public administration that operates together with the private sector (e.g. business) and civil society (e.g. communities, associations, scientific or political organizations, religious institutions). Their cooperation, apart from addressing effectively direct and indirect needs, would be paradigmatic in reflecting in the administration of the synchronic and diachronic diversity and the evolving complex, dynamic and non-phobic identity.

More specifically the local cooperation is formed around, a "bridge of coexistence" that covers living and social needs. Immigrants and refugees' basic needs (security, shelter, health, sustenance and education) are usually covered through state actions in the host society, while social needs (such as interaction and the sense of belonging to a group), are normally provided through participation in their own community. But as long as they remain "enclaved", this informal division is extended, thus, consolidating a gap with multiple consequences. In the long run, this leads to situations where Others are still in a peculiar ghettoization and a dual "dependence": on state welfare regarding their material needs and their community regarding social needs. Therefore, bridging the gap constitutes a critical challenge so as to create a positive and productive interaction that will allow new Others to become members of a culturally diverse, tolerant and creative society.

In the middle point of that "coexistence bridge", stand those organizations that genuinely represent Others and especially the traditional ones since they have an accumulated experience of understanding issues of identity diversity and otherness. While acknowledging weaknesses, such as subjectivity, personal and political aspirations etc., we cannot overlook their capacity in understanding both the majority and minority sides of the society. Their ability of adaptation facilitates the effective addressing of needs in a way that avoids resentment from other sides. An indicative example is the efforts by the Rhodian Muslim cultural association to offer Turkish language courses to its members or request a curriculum change in order to address their impression regarding the dissociation from their cultural capital.

Through the UnDRho research project it became clear that public space can function as a place of mutual understanding. Attitudes towards diversity are "constructed" through public participation, interaction in everyday practices, as well as by the overall way Us and Others are perceived in the public sphere (see also Appiah 2016, p. 100). However, it is necessary since its absence may lead to stereotypes and prejudices and this in turn threatens to undermine the positive perception of diversity. Essential interaction depends on the quality and frequency of contacts in order to shape perceptions and behaviors. Interviews with the subjects of the UnDRho project, focusing on the inter-community relations, demonstrated that as familiarity develops, diversity is perceived as a "normal" condition with corresponding behaviors and interactions in the public space. 


\section{Creating game changing policies under the local prism in Greece}

Under the light of the previous analysis, herewith policy recommendations focus on the apparent interconnection between local realities and the transformation of attitudes towards diversity through an innovative use of the local context.

Often, discussion regarding the integration of the Others focuses on national policy. However, national policy outlines a framework that is up to the local governments to implement, adapt, modify, re-negotiate or consult with individual players at the local level. Local governments, despite the suffocating mayor-centric institutional framework in Greece, have a significant share in resolving integration issues, as they usually possess the political reflexes and the ability to be closer to a wide range of actors, namely the central administration and the Others, while operating through a "bottom-up" approach which often offers the opportunity to act in innovative ways. By being closer to citizens, they have a better, although sometimes cursory and superficial, view of the challenges and how to trigger social integration, how to facilitate the pertinent actions in order to be functional and successful and how to ensure benefits for the local community. So, while it is important to keep local authorities informed on national integration policies, it is equally important to focus on designing policies custom-made for the field in which they will be implemented. There are indeed limitations regarding the freedom of the local authorities to design policies due to the unclarified legal framework, which becomes even more blurred given the economic "subordination" to the central government. In any case, it is of utmost importance to increase the success rate of local integration actions. This actually depends on the local background on consent and acceptance, the availability of human and material resources, the density and innovativeness of the local networks mobilised to contribute, the involvement of different actors in the formulation and implementation of policies, the extent of the needs to be covered, and the required speed of response to those needs.

An approach demonstrating a positive image of the role of the local communities in the management and integration of Other, along with the overall positive trends created by successful inclusion policy, could contribute to developing consent and acceptance. The very shifting of the each-time local community's perception from caution, restraint and introspection towards a more creative approach may trigger in time a favorable outlook in socio-economic terms. In the current situation of sizable migration flows, the communication of new messages to form a positive, unifying, image can cause beneficial results towards an inventive management of integration.

Since perceptions that shape processes, attitudes and ideas are complex and multifaceted, efforts for their transformation should also be multi-leveled, tailored to the specific context, based on knowledge of psychological dimensions that govern the behaviors and have sufficient duration and continuity. For that reason, communication should target the specific local features that could become the basis for developing a positive narrative; such as the intercultural society of Rhodes. Through research, analysis and interpretation of particular conditions one can identify social groups that would trigger the work of convergence, or become the "bridge of coexistence". The aim is not to recruit volunteers but to enable wider social groups to subconsciously contribute in the integration of Others through empathy and example. Moreover, the "humanitarian but not contributing" approach by the Rhodian Muslims that could possibly empathise demonstrates the need for active communication strategy.

The need for systematic highlighting of the positive contribution of Others to the host society should be accompanied by the public understanding of the reasons for which migrants had to abandon their homelands. Public opinion tends to be dominated by prejudices and negative 
stereotypes such as the burden on the social welfare system, the loss of job places, the rise of criminal rates or public health issues that to some degree resonate racist and populist perceptions. Despite objective evidence to the contrary, policies combating such stereotypes and prejudices are far from successful. In this respect, there is need for coordinated and farreaching initiatives towards thinking "outside the box" as well as promoting positive experiences from cooperation and coexistence. The coexistence of Rhodian Christians and Muslims has already provided the empirical basis for the deconstruction of stereotypes locally and a case study for the refugees and immigrants.

The very inclusion of diversity principles in local government policies and activities, and the undertaking of concrete tasks can lead to a positive outlook. Beyond declarations for the adoption, by the local authorities, of a positive stance towards diversity, what really demonstrates a commitment to inclusion and participation is the formation of a basis for action by the local authorities with explicit commitments on timetables, policies and services, and their implementation. The danger in that case is the politically correct rhetoric that is usually coupled by neglect in practice which further leads to complacency. Still, as symbols of the values and expectations of a society, local leaders (Mayor, elected counsels, representatives of social institutions etc.) when showing public support to the integration of Others, they create positive predisposition and sensitivity that may prove useful not only in terms of a tolerable life, but also in terms of functional communication and prosperity for the entire local community.

Newcomers should not be only information recipients. They need to become shareholders and co-creators of conditions that fulfill their needs and shape their prospects for a new life at the host country. This works as a catalyst facilitating participation of the new Others in education, work, cultural and social life, as well as the realization of their economic independence.

Similarly, despite practical difficulties, the development of local partnerships with organizations representing Others can bring together people with different cultural backgrounds. This could also offer all citizens an opportunity to express their common concerns and to build a mutually reinforcing relationship with the view to formulate policies. In that way, a link is created between state/local communities and Others, as well as a forum for debate and expression of opinions that can encourage integration in social life. On that basis, actions promoting cultural diversity and combating discrimination are stimulated, cooperation with organizations of Others is inspired, cooperation to jointly organise awareness activities is encouraged, new approaches such as the promotion of cultural and social mediators is encouraged and finally, a "toolbox" of good practice within (and between) local communities is established.

The prism of local dimension sheds light on the role played by the educational system too. Interviews with the Rhodian Muslims and the special focus on their evaluation of the parallel curriculum support two directions regarding the management of the education of the Others. Addressing otherness involves the cultural empowerment of the bearer of diversity through the re-connection with his/her cultural capital as well as the cultural integration in the new (or diversified for the traditional Others) environment. Our long list of educational policy recommendations focuses on the support of the schooling system to improve both the learning capacity of diversified students and the integration of their families. Teachers should be "equipped" with "equipping" teachers with intercultural skills while national-centric history classes and Christianity-centric religious classes could take account of ecumenical views, at least locally, without the need for a centrally organised curriculum change. At the same time, 
the school could become one of the focal points for the building of social interrelation especially for families through "mediators" that share some cultural characteristics as in the case of Rhodian Muslims. On the other hand, beyond local policies, the educational system needs to "introduce" contemporary issues like immigration to the school-age children.

The input of the Rhodian Muslims in the formulation of the policy suggestions of the UnDRho research project becomes apparent with the issue of addressing the religious dimension of the immigrant communities. What is important is the prevention of radicalisation in the host countries. Aside the educational policies regarding the understanding of religious diversity and the intercultural communication skills, it is necessary to ensure that immigrant collectives will be open and inclusive. The formal and informal organisations established by immigrants are both a normal development and a positive one. It is important, though, to avoid the tendency towards introvert communitarianism that may lead to ghettoization. The involvement of the local diversity in those organisations, based on a common cultural characteristic such as religion in the case of the Rhodian Muslims, will cover both the need for collective representation and mitigation of otherness, traditional or new, as well as the mediation with the local society.

\section{CONCLUSIONS}

Political and economic instability in Central Asia and the Middle East has created a wave of migration to Europe, which has become a constant destination for migrants. In addition to that, the ongoing economic crisis places the need to provide for the integration of the increasing number of population in movement in a context of multiple social challenges. This applies even more for the Greek society, despite the fact that due to geographical location and history has witnessed diversity, the instigation of a process of othering, as well as harmonious coexistence as highlighted by the case of Rhodes.

Although, a safety net of policies and institutional arrangements for the protection of population on the move and the societal empowerment of diversity has been gradually developed, it is understood that there is a further need to enrich practices. At the same time, established practices, which have driven the climate of fear and suspicion that succeeded the multicultural euphoria need to be "renegotiated". The need to understand cultural diversity is more urgent than ever, unfortunately, under the pressure from the recent experience of terrorism acts in Europe. There is a need for focus and action in order to gain the participation of Others in European societies, as well to reduce indifference towards them. The recognition of the importance and value of culture bore by the Other is also of critical importance. Therefore, effort is needed to create conditions that stress on mutual recognition, acceptance, shared responsibility and creative coexistence. Today, approaching Others presupposes intervention in critical areas, and local communities have a particular say and a role in this.

\section{BIBLIOGRAPHY}

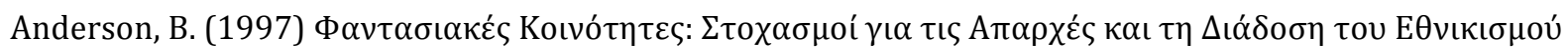
[Imagined Communities: Reflections on the Origins and Spread of Nationalism], Nefeli, Athens.

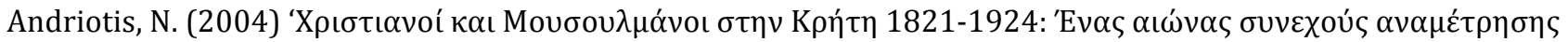

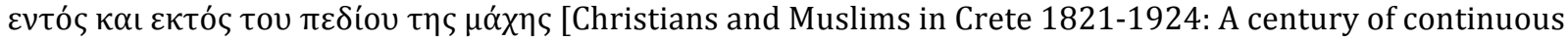
confrontation within and outside of the battlefield], Mnimon, vol. 26, pp. 63-94.

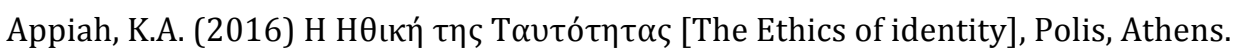

Balibar, E. (2011) 'Our European incapacity', Open Democracy, 16 May 2011. Available online at https://www.opendemocracy.net/etienne-balibar/our-european-incapacity.

Balibar, E. (2003), We, the People of Europe? Reflections on Transnational Citizenship, Princeton University Press, New Jersey. 
Kimourtzis, P., Kokkinos, G., Papageorgiou, I. V., \& Kypriotis, D. (2017). Crisis, Otherness and Integration. Local policies in South Eastern Europe: The case of Rhodes island. Advances in Social Sciences Research Journal, 4(5) 146-161

Barnavi, E. (2008) Les Religions Meurtrières, Flammarion, Paris.

Bauman, Z. (2010) Living on Borrowed Time: Conversations with Citlali Rovirosa-Madrazo, Polity Press, Cambridge.

Bellais, R. (2016) 'The European refugee and migrant crisis as an asymmetric conflict? What border management can learn from military operations', paper presented at the conference "Borders, Walls and Violence: Costs and Alternatives to Border Fencing", Montreal, 2-3 June.

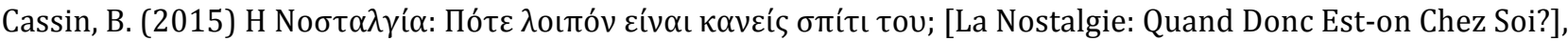
Melani, Athens.

Chapman, M., McDonald, M. \& Tonkin, E. (1989) 'Introduction' in History and Ethnicity, eds M. Chapman, M. McDonald, \& E. Tonkin, Routledge and Kegan, London, pp. 1-21.

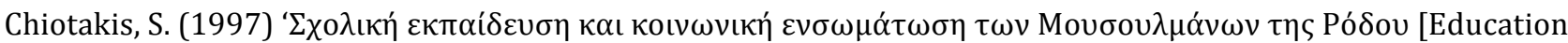
and Social Integration of the Rhodian Muslims]', Synhrona Themata, vol. 63, pp. 79-83.

Cowan, J. K. \& Brown, K. S. (2000) 'Introduction' in Macedonia: The Politics of Identity and Difference eds J. K. Cowan, Pluto Press, London, pp. 3-27.

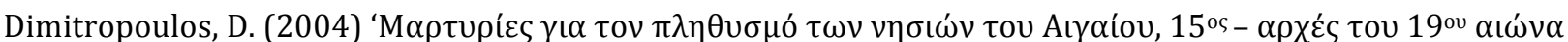
[Evidence for the population of the Aegean islands, $15^{\text {th }}$ - beginning of $19^{\text {th }}$ century]', Tetradia Ergasias Kentrou Neoellinikon Ereunon/EIE, vol. 27, pp. 9-360.

Dirlik, A. (2007) 'Global South: Predicament and Promise', The Global South, vol. 1, no. 1, pp 12-23.

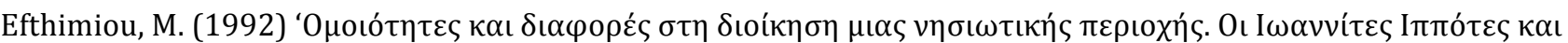

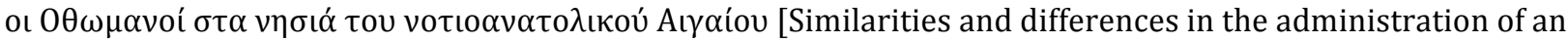
island region. The St John Knights and the Ottomans on the islands in the southeastern Aegean]', Mnimon, vol. 14, pp. 21-48.

Georgallidou, M., Kaili, H. \& Celtek, A. (2013) 'Code alternation patterns in bilingual family conversations: implications for an integrated model of analysis', in Language Variation-European Perspectives IV, eds P. Aurer, J. Caro \& G. Kaufman, John Benjamins, Amsterdam, pp. 117-128.

Georgallidou, M., Kaili H. \& Celtek A. (2006) ‘Г

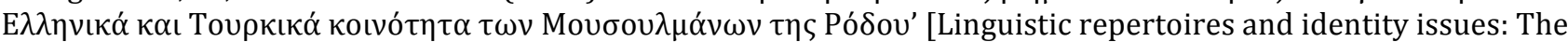
bilingual in Greek and Turkish community of the Muslims in Rhodes]' paper presented at the conference

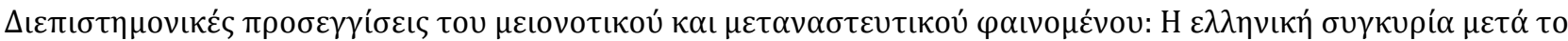

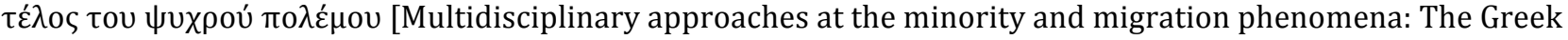
conjunction after the end of the cold war], Athens, 15-17 December.

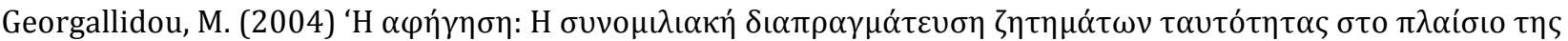

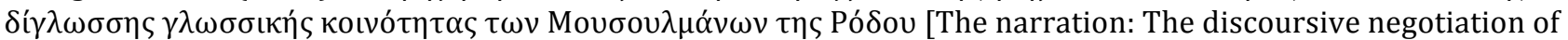
identity issues in the framework of the bilingual community of the Muslims of Rhodes]', in Proceedings of the 6th International Conference on Greek Linguistics, e-book available online at: http://www.philology.uoc.gr/conferences/6thICGL/gr.htm, Rethymno.

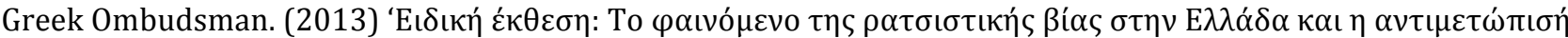
тou' [Special report: The phenomenon of racist violence in Greece and its addressing]', available at: https://www.synigoros.gr/resources/docs/eidikiekthesiratsistikivia.pdf

Gole, N. (2013) 'Islam, European Public Space and Civility', in Religion in the New Europe, ed K. Michalski, CEU, Budapest.

Hai, Y. (2008) 'Revenge of young Muslims', The Sunday Times, 6 April.

Halikiopoulou, D. (2007) 'The changing dynamics of religion and national identity: Greece and Ireland in a comparative perspective', PhD Thesis, London School of Economics.

Held, D., Goldblatt, D., McGrew, A. \& Perraton, J. (1999) Global Transformations, Polity Press, Cambridge.

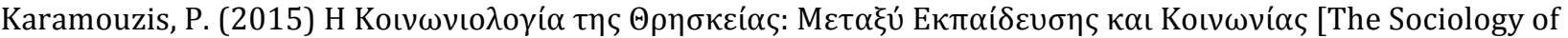
Religion: Between Education and Society], Ellinika Akadimaika Syggrammata Kallipos, Athens.

Kaurinkoski, K. (2012) 'The Muslim communities in Kos and Rhodes: Reflections on social organization and collective identities in contemporary Greece', in Balkan Encounters, Old and New Identities in South-Eastern Europe. Slavica Helsingiensia 41, eds J. Lindstedt \& M. Wahlstrom, University of Helsinki, Helsinki. pp. 47-69. 
Kokkinos, G., Kimourtzis, P. Karamouzis, Papageorgiou, F. I., Kypriotis, D., Trantas, P., Papageorgiou V. I.,

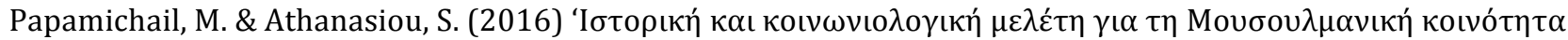

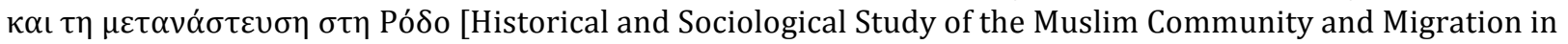
Rhodes]', Unpublished report of the Understanding Diversity in Rhodes: Traditional and New Others (UnDRho) research project.

Kokkinos, G., Kimourtzis, P. Karamouzis, Leros, A., Papageorgiou, F. I., Kypriotis, D., Trantas, P., Papageorgiou V. I.,

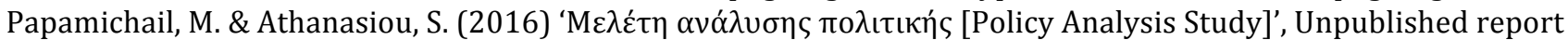
of the Understanding Diversity in Rhodes: Traditional and New Others (UnDRho) research project.

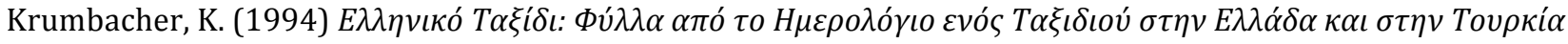
[Greek Voyage: Excerpts from the log of a Journey in Greece and Turkey], Katoptro-Istoritis, Athens.

Kurth. J. (2007) 'Religion and National Identity in America and Europe', Society, vol. 44, no. 6, pp. 120-125.

Lantza, E. (2011) 'The Muslims of the Dodecanese islands: A non-officially recognised minority', MSc Thesis, Istanbul Bilgi University.

Manis, T (2008) 'Lecturer of Turkish language in Rhodes breaks old stereotypes', Turquie Europeenne, 19 March. Available online at: http://turquieeuropeenne.eu/lecturer-of-turkish-language-in-rhodes-breaks-oldstereotypes.html

Manzoor, S. (2005) 'We've ditched race for religion', The Guardian, 11 January.

Mitchell, C. (2013) Religion, Identity and Politics in Northern Ireland: Boundaries of Belonging and Belief, Ashgate, Oxford.

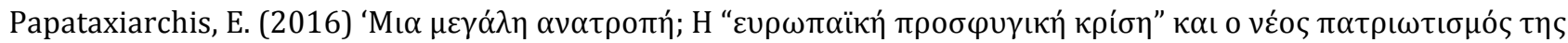
" $\alpha \lambda \lambda \eta \lambda \varepsilon \gamma \gamma$ úms"' [A great reversal? the "European refugee crisis" and the new patriotism of "solidarity"]', Synhrona Themata, vol. 132-133, pp. 7-28.

Peri, Y. (2012) 'The "Religionization” of Israeli Society: Introduction', Israel Studies Review, vol. 27, no. 1, pp. 1-3.

Putnam, R. (1993) Making Democracy Work: Civic Tradition in Modern Italy, Princeton University Press, Princeton.

Roy, O. (2013) 'Islam in Europe: Clash of Religions or Convergence of Religiosities?', in Michalski in Religion in the New Europe, ed K. Michalski, CEU, Budapest.

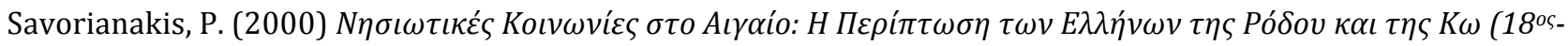

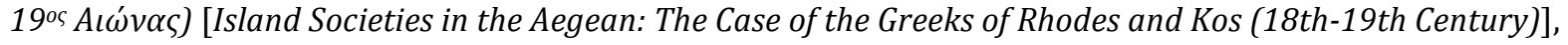
Trohalia, Athens.

Souryal, S. (1987) 'The Religionization of a Society: The Continuing Application of Shariah Law in Saudi Arabia', Journal for the Scientific Study of Religion, vol. 26, no. 4, pp. 429-449.

Sutton, E. D. (1998) Memories Cast in Stone: The Relevance of the Past in Everyday Life, Berg, Oxford.

Taras, R. (2009) Europe Old and New: Transnationalism, Belonging, Xenophobia, Rowman \& Littlefield Publishers, Lanham.

Taylor, C. (2007) A Secular Age, Harvard University Press, Massachusetts.

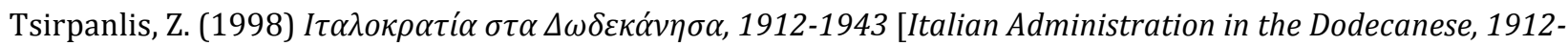
1943], Municipality of Rhodes, Rhodes.

Tsitselikis, K. (2011) Old and New Islam in Greece. From Historical Minorities to Immigrant Newcomers, Martinus Nighoff, Leiden.

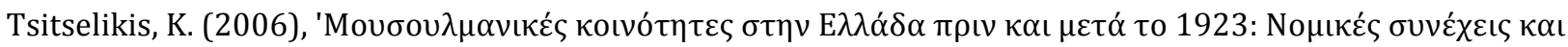

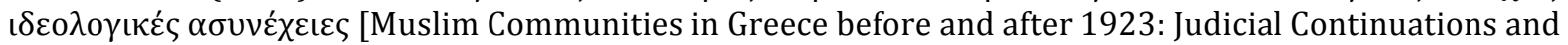

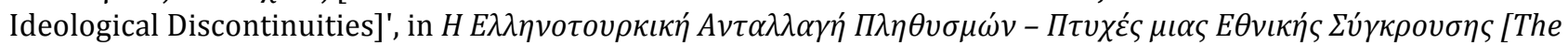
Greek-Turkish Population Exchange: Aspects of a National Conflict], Research Centre for Minority Groups, Athens, pp. 368-387.

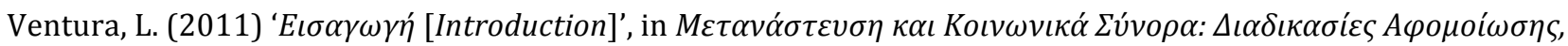

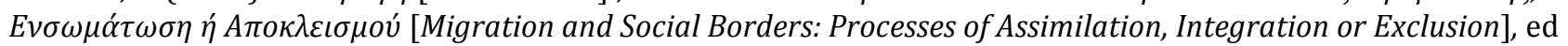
L. Ventura, Nissos, Athens, pp 1-17. 